\title{
Optimization of the Production Planning and Trade of Lily Flowers at Jan de Wit Company
}

\author{
José Vicente Caixeta-Filho • Jan Maarten van Swaay-Neto • \\ Antonio de Pádua Wagemaker \\ Universidade de São Paulo, Escola Superior de Agricultura "Luiz de Queiroz," Avenida Pádua Dias, 11, \\ 13418-900 Piracicaba, SP, Brazil \\ Interativa S/C Ltda., Rua Campo do Pouso, 1189, 13825-000, Holambra, SP, Brazil \\ Wagemaker Consultoria Ltda., Rua Santo Antonio, 821, 13830-000, Santo Antonio de Posse, SP, Brazil \\ jvcaixet@esalq.usp.br • interati@dglnet.com.br • wagemak@bestway.com.br
}

Jan de Wit Company implemented a decision-support system based on linear programming as a production-planning and trade tool for the management of its lily flower business. The LP maximizes the farm's total contribution margin, subject to such constraints as marketdefined sales limits, market requirements, characteristics of the production cycle duration, technical requirements, bulb inventory, and greenhouse limitations. The main decision variable to be calculated is the number of flower beds in a specific greenhouse, from a specific bulb batch, of a specific variety, for a specific purpose, taking into consideration planting and expected harvesting weeks. Between 1999 and 2000, company revenue grew 26 percent, sales increased 14.8 percent for pots of lilies and 29.3 percent for bunches of lilies, costs fell from 87.9 to 84.7 percent of sales, income from operations increased 60 percent, return on owner's equity went from 15.1 to 22.5 percent, and best quality cut lilies jumped from 11 to 61 percent of the quantities sold. The system also suggested changes in the product mix.

(Industries: agriculture, food. Programming: linear, applications.)

$\mathrm{L}$ ike most industrial sectors, the ornamental plant and flower industry has experienced the effects of globalization. In Brazil, this has meant an increase in competition; greater production in such traditional areas as the municipality of Holambra in São Paulo State; the creation of new regional production areas; the installation of national and international companies to supply seedlings and seeds; government grants for the production of flowers and plants, helping to increase the incomes of small- and medium-sized nurseries and exporters; imports of natural and artificial flowers and plants; and exaggerated promotions of flowers. The increased competition has caused price reductions, which are seen as a measure of quality.

The farmers cannot ignore the current market changes and the need to use tools to help them make decisions, which will lead to closing good deals, increasing profits, reducing costs, and improving quality. We developed a computer program using mathematical optimizing models to help a lily producer from the Holambra region to make such decisions.

\section{The Problem}

Producer Johannes Petrus W. de Wit, general manager and owner of Jan de Wit Company, had good reasons for celebrating the coming of 2001. By the end of 2000, Jan de Wit Company, Brazil's largest producer of Oriental and Asian lily flowers, had increased revenues by 26 percent in comparison with 1999. It achieved this 


\section{CAIXETA-FILHO ET AL.}

gain in a well-cultivated area that occupies two hectares (20 thousand square meters) in Holambra, the City of Flowers, 160 kilometers from Sao Paulo, in Brazil.

The firm's gains resulted from its investment in computerized production planning based on a mathematical model developed specially for its many needs. Producing about 420,000 pots and 220,000 bunches of lilies per year, Jan de Wit Company had trouble planning production manually. So many parameters were involved that the company had to split the planning to control the productive process.

The final customer is the main agent of the lily business (Figure 1); Brazil's 180 million inhabitants spend US\$ 1.1 billion per year on flowers, mostly at the retail level (exports of Brazilian flowers are not significant yet).

The flower retailers, mainly flower shops, supermarkets, and garden centers, number around 10,000. They purchase flowers from distributors, about 400 companies. At the six wholesale marketplaces in Brazil, around 3,600 flower producers (occupying 4,500 hectares) bring their flowers to sell to the distributors.

To produce the lily flowers Jan de Wit Company needs bulbs - vegetative propagation structures-normally furnished by bulb wholesalers in Holland. These wholesalers offer many varieties of bulbs, which they acquire from bulb producers, most also located in Holland.

Bulb supply is a critical aspect in the lily business chain. It takes two years to produce a bulb big enough to produce flowers. The bulb grows underground at the base of the lily plant. Normally each plant produces one bulb, which also acts as a storage organ that holds carbohydrates, nutrients, and water for the nextgeneration plant. From the bulb, the flower develops.

Brazil currently does not cultivate great quantities of bulbs. Jan de Wit Company gets 95 percent of its bulbs from Holland, where it also stores its bulb stock. The company annually imports 3.5 million bulbs of approximately 50 varieties of potted lilies (to be sold as flowering plants) and cut lilies (to be sold in bunches). Every month, as scheduled, the Dutch suppliers send part of this stock. The entire stock and the contents of each shipment are divided into batches. Each batch contains a determined number of bulbs, furnished by a specific bulb producer, from a specific harvesting year, variety, and bulb size. Jan de Wit traces all bulb batches from the moment of purchase until the moment the lilies are harvested.

Jan de Wit Company began working with lily flowers on a small scale in 1992, when it practically started the culture in Brazil. In 2000, it reached 18,745 square meters of greenhouses, a shed of 1,500 square meters, 1,032 square meters of cold-storage rooms, and a team of around 30 employees.

Jan de Wit Company uses Veiling Holambra, the largest flower wholesale marketplace in Brazil and Latin America, as its only sales vehicle. In 2000, Veiling Holambra had an annual revenue of US\$ 80 million (38 percent of the Brazilian flower market at the producer level). Approximately 250 of the 400 distributors purchase at Veiling Holambra.

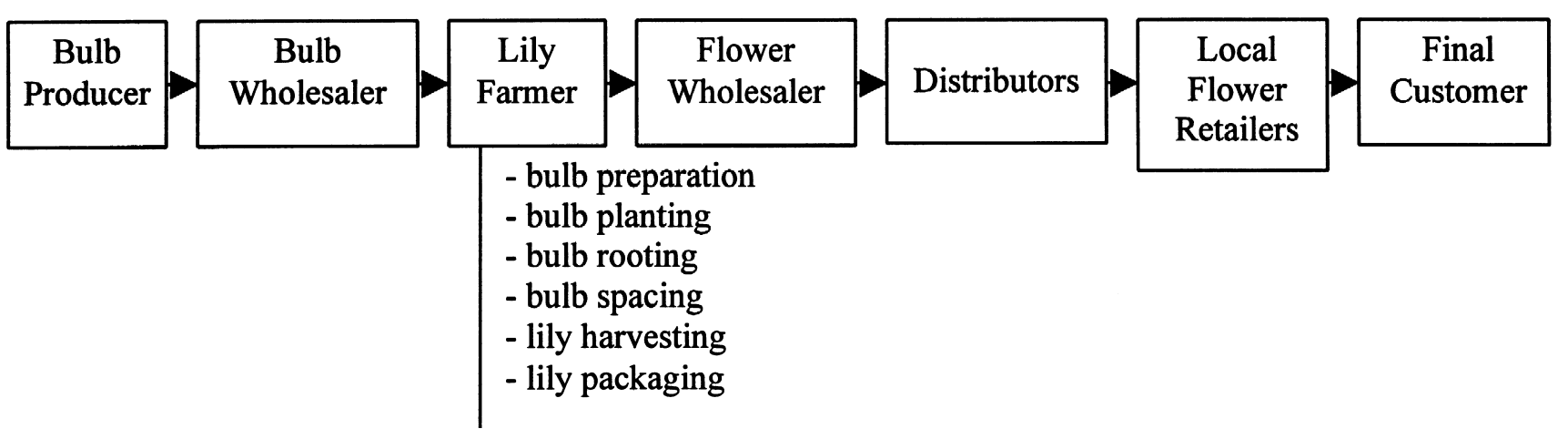

Figure 1: The lily business chain consists of the activities and interactions of seven main players: bulb producers, bulb wholesalers, lily farmers, Veiling Holambra (the largest wholesale market for flowers in Brazil), distributors, local flower retailers, and final customers. 
The Veiling uses two main trading systems: auction and intermediation. The auction is a daily cash market. In the auction room, distributors can buy the flowers passing in front of them under the conditions shown on an electronic panel. Quantities and prices may oscillate considerably. Half of Jan de Wit Company's sales occur at the auction, which provides transparent and market-driven prices. Intermediation is like the futures market. Specialized agents close buy-and-sell contracts between distributors and producers for the

\section{We had to make the executives believe our promises.}

short, medium, and long term. The other half of Jan de Wit Company's sales is made through intermediation, which entails less risk in terms of quantities and prices.

The Veiling also defines the market requirements, for instance, the selling unit, the minimum number of buds and stems per bunch or per pot, quality standards for top quality flowers (no qualifying remarks) and second and third quality flowers (depending on the qualifying remarks, for example, "some spots on the leaves").

Based on daily contact with its clients at Veiling Holambra, on sales history, on current fashion trends, and on the economic environment, the company identifies market opportunities in terms of weekly sales quantities and prices for each lily variety.

To select the best market opportunities, those it will exploit, the company must consider the technical and operational restrictions on its production process.

Oriental and Asian lily flowers are temperateclimate flowers suited to colder regions, and growing them in Brazil is not easy, requiring a special process to produce good-quality flowers. Before planting, the bulbs must be held for about two months at the right temperature (bulb preparation); after that, they may be planted or stored frozen at less than $2^{\circ} \mathrm{C}$. After planting, the bulbs remain in a $12^{\circ} \mathrm{C}$ environment for two weeks until the stem roots form (bulb rooting), and then they are moved to the greenhouse (bulb spacing), which has a temperature of $25^{\circ} \mathrm{C}$.

Fundamental to the business is buying the right bulbs and volumes during the three month period of the Dutch bulb harvest. The company must crosscheck its market opportunities and its technical and operational restrictions to determine an optimal sales and production plan and to calculate the number of bulbs of each variety and each of three different sizes to buy.

It is also critical to plant the bulbs during the right week. Depending on the variety, the bulb size, and the planting week, the production cycle can vary from six to 16 weeks. Basically, to transform the optimal sales and production plan into reality, Jan de Wit Company must plant the right bulbs during the right week.

To make efficient use of its greenhouses, the company must have very strict and accurate planning. It must take into consideration the seasonal pattern of the flower market, with its peaks at specific dates, such as Mother's Day, Easter, All Soul's Day, and Christmas. In addition to these seasonal characteristics, the flower market is also affected by trends for certain varieties and colors, which means that the producer must be alert to the market's moods at the moment of planning.

The problem to be solved can be stated as follows: How can Jan de Wit Company best exploit market opportunities, respecting technical and operational restrictions, managing the trade and production cycle, and optimizing its financial results?

\section{The Role of Operations Research}

The history behind this project is very interesting. In February 1997, Caixeta-Filho published a short article, "Modeling, through operations research, in agribusiness systems," in a student journal of the University of São Paulo. This article attracted the interest of SwaayNeto, a flower-business management consultant who had not previously been familiar with operations research. Swaay-Neto phoned Caixeta-Filho to discuss the use of operations research models in the flower business. He ended up becoming one of CaixetaFilho's students in a class on linear programming, offered to graduate students in applied economics at University of São Paulo. He concluded the course by presenting a final paper entitled "Gladiolus bulb production planning." After that, Swaay-Neto invited Caixeta-Filho to develop more accurate modeling approaches to applying mathematical programming to 


\section{CAIXETA-FILHO ET AL.}

Jan de Wit Company

some flower-sector problems. They did further work on the "gladiolus case" (Caixeta-Filho et al. 2000), with the help of Ricardo Lopes, who improved the model and developed an Excel worksheet with user-friendly interfaces for data input. This model was implemented at Terra Viva Company. That implementation opened other doors, including that of the lily case.

We started the project in July 1998. The first practical results came in the last quarter of 1998. During the first semester of 1999, we focused on developing an interface for the user capable of generating data for the model from sales and production input. Next, during the second half of 1999, we made the solution found

\section{The firm's contribution margin increased 32 percent.}

by the model more user friendly. Also during 1999, we consolidated the pertinent database. Since January 2000, Jan de Wit Company has been using the system fully, and its benefits are visible.

The project team was composed of Caixeta-Filho, who developed the mathematical model; Swaay-Neto, who acted as project leader and business analyst, oversaw the modeling and programming activities, made tests, and worked on data gathering and project implementation together with Jan de Wit Company; and Wagemaker, who programmed the software and supported the analysis and implementation. Jan de Wit Company provided the financial investment.

The main initial difficulties we faced were related to the communication process as a whole and to the fact that the traditional approach to flower business management did not use operations-research-based models. We had to make the executives of Jan de Wit Company believe our promises ("how can these guys think that a mathematical tool may give better results than ours ...") and understand linear programming (we gave them some formal theoretical classes), and we had to convince them to invest in a completely new project instead of investing in a new greenhouse or irrigation system. During the conceptual development and implementation phases, we had to help the executives understand the process as a whole and redesign their business. We overcame-or at least mitigated- the initial executive resistance by comparing past manually created and inferior solutions with those resulting from feeding the same historical input data into the optimization model.

Initially we concentrated on developing planning tools, and then we looked at questions associated with control. To make this work possible, we formulated a linear programming model to optimize planning and developed a production-control application to facilitate handling of input data and the model results.

We programmed this decision-support system, compatible with Windows, using Visual Basic and supporting it with an Access databank. The system required a minimum configuration of a Pentium 233 $\mathrm{MHz}$ with $32 \mathrm{MB}$ of RAM.

The final linear-programming model, developed in GAMS language (Brooke et al. 1992), used as its objective function an expression of the total contribution margin of the producer. The maximization of this objective should be subject to the following restrictions: upper and lower market-defined sales limits; market requirements (selling unit, minimum number of buds, and minimum number of stems per bunch or pot); characteristics of the production cycle's duration (depending on the variety, this constraint takes into consideration bulb size, bulb origin, sprout length, and planting week); technical requirements (number of bulbs per pot or box and their spacing); bulb inventory; and usage limitations for each type of greenhouse.

The key decision variable to be calculated using this optimization model is the number of flower beds in a specific greenhouse, originated from a specific bulb batch, from a specific lily variety, for a specific use (for example, potted lily or cut lily), taking into consideration the pertinent planting week and the expected harvesting week. The general matrix dimensions involved 120,000 rows, 420,000 columns, and 1,300,000 nonzero elements (Appendix).

\section{The Implementation Process}

The starting point in production planning is to estimate the quantity range of lilies that can be traded each week, detailing the contractual minimum quantities and the maximum and possible quantities to be sold, and the average price for each variety. The producer 


\section{CAIXETA-FILHO ET AL.}

had to make this estimate based on knowledge of the market. This market-driven practice reduces the difference between production and sales and between over- and underproduction.

We took into consideration the fact that the producer has full control over the whole production system. This means that the company can calculate, among other things, the cycle of production, how many flowers each bulb will produce, physical losses, productivity, and costs. These parameters can vary according to such factors as the variety, the time of year, the type of greenhouse, and the environment.

The first stage of planning is to cross-check the estimated sales with the production cycle, identifying all the possible combinations within that time period. The mathematical model is able to recognize these combinations and suggests an optimized production plan, respecting the technical viability and production operational limits. The production plan suggests what, when, where, and how many to plant.

The control functions of the decision-support system should ideally work as aids for the production manager. The production notes and annotations should be minimal but should contain all the information necessary for planning and control.

One of the things the system does is calculate the availability of the flower beds week by week, assuming the company will not plant anything else. The system's primal task is to try to occupy the areas as they become available in the best possible way.

With this drill, we cross-check every theoretically possible planting using the sales forecast and cycle of each variety, resulting in a huge series of combinations. The system indicates which is the optimal combination, maximizing the total contribution margin and considering the occupation of the greenhouses. So, if the company begins growing a six-week-cycle variety on week 41 , it is already known at week 41 that the area will be occupied until week 47 . We add every possibility of occupation until we go beyond the available area and have to discard a few combinations. And which ones do we discard? The ones with the lowest profitability.

For the model to process the information, data must be input from the company data bank regarding lily variety; planting area; estimated sales; cycle; greenhouse type; bulb stock; bulb price; production costs; minimum number of buds and stems; and lots already planted and their characteristics, such as number of bulbs, plant type (cut lilies or potted lilies), date of planting, allocated beds, and estimated harvest.

The main results from the system are the information generated by the linear programming model, such as financial results, sales, levels of greenhouse use, stock utilization, and harvest.

The decision-support system (Figure 2) has been used weekly, usually by company's production and sales management team.

In practice, the company can estimate future sales by product and by week, based on daily contact with customers and their individual sales history, as well as

\section{Return on equity went from 15.1 percent to 22.5 percent.}

fashion trends and the economic scene. Inputting the sales forecast to the system is the beginning of the planning process. Next, the mathematical model is run. After the model produces the optimal solution and its economic result, the company analyzes how the solution meets sales per product, what greenhouses will be used, the consumption of bulbs, and the corresponding dual values. Based on these data and on what it can negotiate with its clients, Jan de Wit Company starts changing the sales per product (minimum and maximum quantities or price) and rerunning the model to improve the result. Before committing to the sales and production plan, the company closes deals with the customers, aiming at a 50 percent presale.

The main subprocesses within production planning are bulb preparation, planting, spacing, and harvesting. The system controls the stage of each batch, issuing production orders, data-collection cards, reports to follow production, and stickers to identify the end products. These tools help management and the operational team to communicate and warrant the execution of each subprocess and the collection of control data, such as the batch of bulbs planted, the quantity of bulbs planted, the type of substrate, the type of packing, the spacing date, the flower bed, the harvesting date, and the number of pots or stems harvested. 


\section{CAIXETA-FILHO ET AL.}

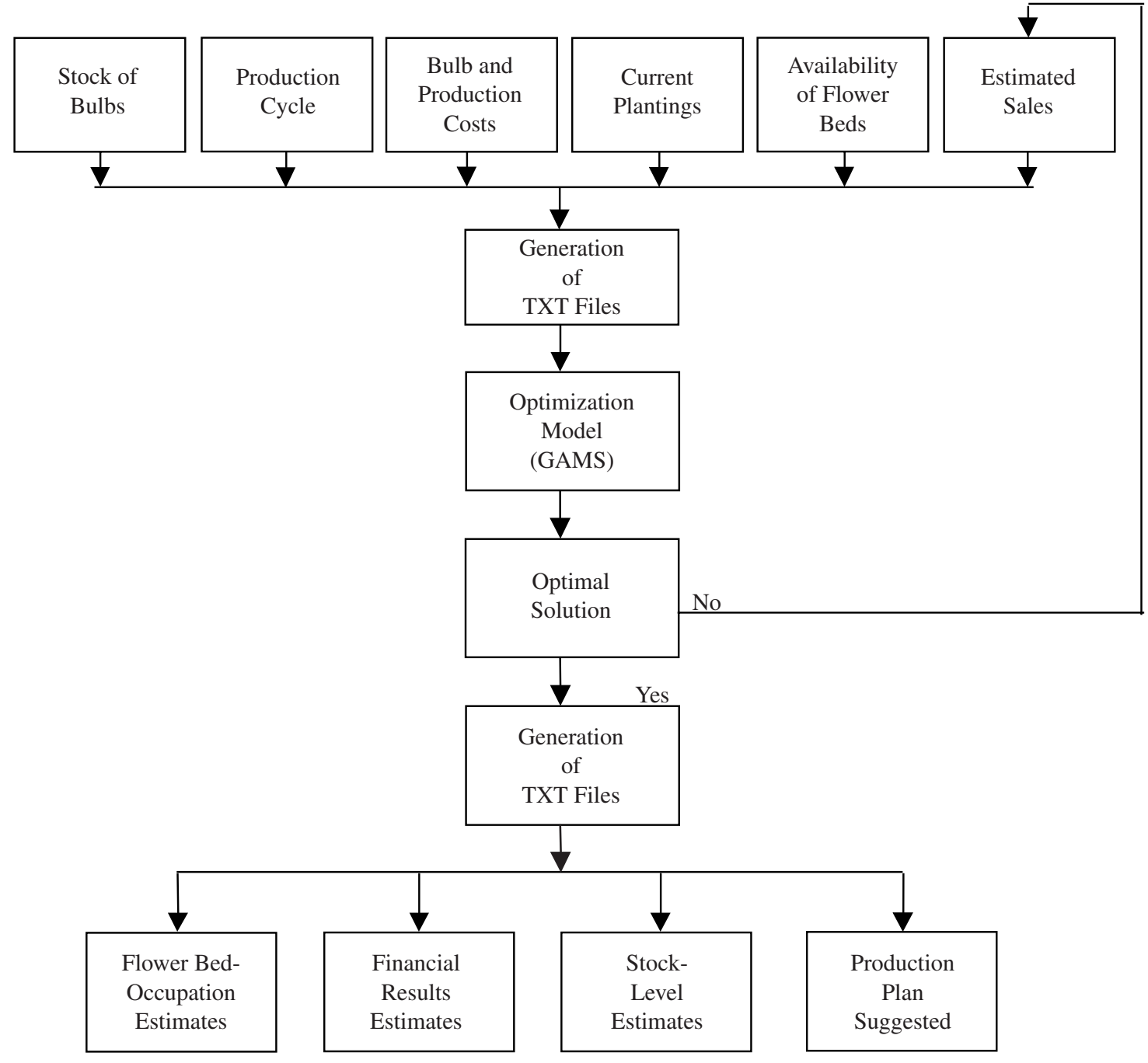

Figure 2: The decision-support system (DSS), based on a linear programming (LP) model, coded in GAMS (Brooke et al. 1992) language, is also the main tool for managing Jan de Wit Company's database. The data for the LP model and the reports generated based on the optimal solution are accessed through user-friendly interfaces.

The system is used throughout the entire process, forcing integration throughout the enterprise and confirming what is usually emphasized in operations research theory. The system's implementation made it possible to redesign and standardize processes, create history in a consistent database, and eliminate the old procedures based only on spreadsheets. Tracing batches is a great strength of the system, because it enables the company to select the suppliers with the best-quality bulbs.

The project was laborious, but the team worked well together. Thanks to the active participation of the top management leaders of the company and the gradual transparency of the results, the other members of Jan de Wit Company accepted the project very well.

\section{Financial Results}

To analyze the impact on the client's business, we defined and calculated key performance indicators based on real data from 1999 and 2000, as well as on the expectations for 2001. 
During these three years, revenue grew 26 percent in 2000, reaching the level of $\mathrm{R} \$ 3,229,542.00$. We expect a further increase of 32 percent in 2001. Sales totaled 484,722 pots and 285,088 bunches in 2000, a positive change of 14.8 percent and 29.3 percent, respectively, in comparison to 1999. Forecasted for 2001 are sales of 986,000 pots and 205,000 bunches, with the company departing from a strategy that focused on potted lilies and on Oriental cut lilies, facing its main competitor which focuses on Asian cut lilies.

The average prices at Veiling Holambra were the same in 1999 and 2000 for potted lilies, R\$3.39 per pot, and varied from $R \$ 5.14$ to $R \$ 5.56$ per bunch for cut lilies. For 2001, the expected average prices are $\mathrm{R} \$ 3.59$

\section{The company greatly reduced the differences between planned results and reality.}

per pot and $\mathrm{R} \$ 7.97$ per bunch. The company expects to get a much higher price per bunch because of its strategy of producing only Oriental cut lilies, which are more expensive than Asian.

Variable costs represented 64.1 percent of sales in 1999 and 62.4 percent of sales in 2000. In 2001, the company expects to reduce variable costs to 53.8 percent by using cheaper growing practices and suffering lower production losses, which in 2000 reached 11.8 percent for potted lilies and 13 percent for cut lilies.

The firm's contribution margin (total sales less variable costs) increased 32 percent in 2000 compared to 1999. This can be considered a direct result of the system, which maximizes the value of this variable.

Fixed costs were R\$613,140.00 in 1999 and R\$ $718,373.00$ in 2000 , with estimates of $R \$ 801,500.00$ for 2001 , a small $\mathrm{R} \$ 83,000.00$ absolute growth compared to 2000. Sales and production levels are growing without significant new fixed costs, characterizing an operational leverage suggested and made possible by the system.

Income from operations was $\mathrm{R} \$ 309,546.00$ in 1999 and $R \$ 495,243.00$ in 2000, a 60 percent increase. The forecast for 2001 is for $R \$ 1,160,000.00$, a growth of 134 percent in comparison to 2000. Regarding return on owner's equity, it went from 15.1 percent in 1999 to 22.5 percent in 2000 .
The number of employees increased from 30 in 1999 to 31 in 2000, with the sales per person increasing from $\mathrm{R} \$ 85,586.00$ to $\mathrm{R} \$ 104,178.00$. For 2001, the company expects to employ a working team of 33 people with an average of $R \$ 128,787.00$ in sales per person.

These results are remarkable given that the Brazilian flower market as a whole in 2000 had a very clear excess of supply, making selling more difficult than it had been in 1999. A comparison of the auction and intermediation prices at Veiling Holambra confirms this situation: In 1999, for instance, average prices were higher at auction than at intermediation, and the opposite was the case in 2000. A related indicator is the value of the quantities that could not be sold at the auction compared to the total sale value: 1.6 percent in 1999 and 4.8 percent in 2000. For 2001, the company expects behavior more like that in 1999.

The trading conditions offered by the Veiling reward the producers that best respond to the needs of their clients, the flower distributors. With the system, Jan de Wit Company managed to balance the needs of its clients and its own restrictions. By improving its planning and control, the company will be able to increase its short-, medium- and long term supply agreements from about 50 percent of its production in 1999 and 2000 to 60 percent in 2001. Thus, the company will lock in the sale price and guarantee its profit on that part of its production. It sells the remainder on the daily cash market, where considerable price oscillations may occur.

\section{Technical Impacts}

The system suggested changes in the product mix. Of the top 10 lily varieties in 2000, only six were in the top 10 in 1999. The company cut the number of varieties it produced from 50 in 1999 to 40 in 2000. It dropped 22 varieties for various reasons (because they were money losers, were unavailable at the bulb market, and so forth) and is testing 12 new varieties for future sales. The market demands a wide range of varieties and is always looking for something new. On the other hand, more varieties mean more complexity in the production process. The system helps Jan de Wit Company to determine the right balance.

Ninety-three percent of the potted lilies the company 


\section{CAIXETA-FILHO ET AL.}

sold in both 1999 and 2000 were of the best quality. Its cut lilies went from 11 percent best quality in 1999 to 61 percent in 2000, with this 50 percent improvement responsible for the better-than-average sale prices in 2000.

Using the system, the company has increased its production and simultaneously improved quality. The production manager can dedicate more time to production itself and less to planning and administration; he has better control over the production process and subprocesses (for example, bulb preparation, planting, spacing, harvesting). The system indicated varieties to plant, the bulb sizes, and planting weeks; it also supported the selection of bulb suppliers in 2000, tracking

\section{It has already been adapted to other flower types.}

results from the bulbs supplied in 1999. Bulb quality improved in 2000 over 1999, with bulb losses before planting going from 1.6 percent in 1999 to 0.5 percent in 2000.

\section{The Time-Saving Impact}

Prior to implementing the decision-support system, Johannes de Wit planned production himself and took several days to plan for a six-month period. Furthermore, the results were less consistent. With the system, he delegates this function in a professional manner. Jan de Wit Company now has fast answers with which it can better negotiate its clients' orders, an important differential in the market.

In the days of the old process, the company relied on creating Excel spreadsheets to help it handle all the variables, an increasingly impossible task. The company doubted that the plan produced would bring the best-possible economic results. Later in the control stage, inconsistencies and questionable data used to surface. Nowadays, with the new tool, the company manages, in a short time compared to the past, to optimize planning, considering all the variables and maximizing economic results. Jan de Wit Company has also greatly reduced the differences between planned results and reality.

Because of uncertain events, climatic or technical problems, the actual production plans do not always materialize. In those instances, the system again shows its value, giving the company an opportunity to take corrective action. Based on the available data, when it has excess production, the company can encourage increased throughput through promotions or refrigerate flowers to sell days later, when it expects a shortage. In case of shortage, Jan de Wit Company can warn its clients in advance.

These measures enhance the company's image and help it to develop a market for products with the Jan de Wit brand. They increase clients' satisfaction and reduce loss of capital and other problems in the whole chain.

\section{Concluding Remarks}

Jan de Wit's improved results in 2000 were not due to a better-behaved market, which was weaker in 2000 . They were also not related to any technical changes in the production process. They can only be the consequences of better management at Jan de Wit Company, whose chief new tool is the DSS we developed.

The executives of Jan de Wit Company testify that they are convinced that the optimization system is their main working tool for managing both trade and production processes. Clients of the company, the distributors, also realize significant benefits because they can buy and sell their products in advance, ensuring volumes, prices, and margins. Their clients, the retailers, also benefit because their orders are guaranteed. This improves results throughout the chain, from retailer to producer.

Jan de Wit Company can now make important investments in the continuity of its business and the improvement of its product's quality, for example, by cooling the sorting and packing area.

The company faces growing competition, with decreasing margins, requiring greater professionalism from all the companies in the business. According to testimony from Johannes Petrus W. de Wit, "companies in the flower business that don't wake up to planning and control systems risk almost unsurpassable capital losses, endangering their continuity and damaging the market." 


\section{CAIXETA-FILHO ET AL.}

Jan de Wit Company

Regarding further developments, we envisage possibly adjusting report formats and eventually the modeling structure. Portability deserves special attention in further developing the system. The gladiolus bulb model (Caixeta-Filho et al. 2000) was the seed for this lily model. The lily model is much bigger and more comprehensive, and it has already been adapted to other flower types (chrysanthemum flowers, for instance). Recently, we were asked to evaluate how the modeling structure could be applied to lettuce greenhouses.

\section{Appendix: General Linear Program Formulation}

The goal of the linear programming model is to maximize the farm's total contribution margin, taking into consideration the pertinent constraints related to such factors as upper and lower marketdefined sales' limits; market requirements (selling unit and minimum number of buds and minimum number of stems per bunch or pot); bulb inventory; characteristics of the production cycle's duration; technical requirements (number of bulbs per pot or box and their spacing); usage limitations for each type of greenhouse.

The mathematical formulation of the model follows.

\section{Indices Related to the Main Sets}

$j$ stands for each bulb batch;

$v$ stands for each lily variety;

$g$ stands for the specific use of the lily (potted lily or cut lily);

$t$ stands for the week in the year;

$i$ stands for the planting week in the year; and

$l$ stands for the expected harvesting week in the year.

\section{Main Parameters (Data)}

$P R E C O_{l v g}=$ expected price for the lily variety $v$, from group $g$, in the harvesting week $l$;

$V M A X_{l v g}=$ maximum sales level for the lily variety $v$, from group $g$, in the harvesting week $l$;

$C P R E V_{\text {lvg }}=$ expected harvests for the lily variety $v$, from group $g$, in the harvesting week $l$;

$V M I N_{\text {lvg }}=$ minimum sales level for the lily variety $v$, from group $g$, in the harvesting week $l$;

$P E R D A_{\text {jvgil }}=$ level of physical loss for the lily variety $v$, from bulb batch $j$, from group $g$, planted in week $i$, and with expected harvest in week $l$;

$B O T O E S_{\text {jvgil }}=$ number of buds for the lily variety $v$, from bulb batch $j$, from group $g$, planted in week $i$, and with expected harvest in week $l$;

$D E N S_{\text {jugil }}=$ density measure adopted for the lily variety $v$, from bulb batch $j$, from group $g$, planted in week $i$, and with expected harvest in week $l$;

$E S P A C_{\text {jvgil }}=$ spacing measure adopted for the lily variety $v$, from bulb batch $j$, from group $g$, planted in week $i$, and with expected harvest in week $l$;

$F V_{\text {jugil }}=$ binary value that identifies whether lily variety $v$, from bulb batch $j$, from group $g$, planted in week $i$, and with expected harvest in week $l$, belongs to the potted lily group;

$F C_{\text {jvgil }}=$ binary value that identifies whether lily variety $v$, from bulb batch $j$, from group $g$, planted in week $i$, and with expected harvest in week $l$, belongs to the cut lily group;

$Q L S P_{j v g i l}=$ binary value that identifies whether lily variety $v$, from bulb batch $j$, from group $g$, planted in week $i$, and with expected harvest in week $l$, is compatible with the plane greenhouse with temperature and luminosity control $(Q L S P)$;

$Q L S I_{j v g i l}=$ binary value that identifies whether lily variety $v$, from bulb batch $j$, from group $g$, planted in week $i$, and with expected harvest in week $l$, is compatible with the inclined greenhouse with temperature and luminosity control (QLSI);

$P F_{\text {jugil }}=$ binary value that identifies whether lily variety $v$, from bulb batch $j$, from group $g$, planted in week $i$, and with expected harvest in week $l$, is compatible with the plane greenhouse $(P F)$;

$B U L B_{j}=$ availability level of bulb batch $j$;

$C B U L B_{j}=$ cost to purchase bulb batch $j$;

$C C A N T_{j v g i l}=$ costs associated with the flower beds to be used by lily variety $v$, from bulb batch $j$, from group $g$, planted in week $i$, and with expected harvest in week $l$;

$M_{I N B O T O E S_{j v g i l}}=$ minimum quantity of buds to be accepted for lily variety $v$, from bulb batch $j$, from group $g$, planted in week $i$, and with expected harvest in week $l$;

MINHASTE $E_{\text {jvgil }}=$ minimum quantity of stems to be accepted for lily variety $v$, from bulb batch $j$, from group $g$, planted in week $i$, and with expected harvest in week $l$;

OOEQLSP $P_{t}=$ availability of flower beds in greenhouse type $Q L S P$ at week $t$;

$O O E Q L S I_{t}=$ availability of flower beds in greenhouse type QLSI at week $t$;

$O O E P F_{t}=$ availability of flower beds in greenhouse type $P F$ at week $t$.

\section{Main Decision Variables}

$R B R U=$ gross economic result;

$R E C$ = total revenue;

CTOT = total costs;

$C B=$ bulb costs;

$C F C=$ cut lily costs;

$C F V=$ potted lily costs;

$Q T_{j v g i l}=$ quantity of bulbs from batch $j$, for lily variety $v$, from group $g$, planted in week $i$, and with expected harvest in week $l$;

QTGRUPO $_{\text {jvgil }}=$ quantity of potted lilies or cut lilies obtained from bulbs from batch $j$, for lily variety $v$, from group $g$, planted in week $i$ and with expected harvest in week $l$;

NUMCANT jvgil $_{\text {il }}=$ total flower beds occupied by bulbs from batch $j$, for lily variety $v$, from group $g$, planted in week $i$ and with expected harvest in week $l$;

NUMCANT $1_{\text {jvgil }}=$ total flower beds in greenhouse type QLSP, occupied by bulbs from batch $j$, for lily variety $v$, from group $g$, planted in week $i$, and with expected harvest in week $l$;

NUMCANT $2_{\text {jvgil }}=$ total flower beds in greenhouse type QLSI, occupied by bulbs from batch $j$, for lily variety $v$, from group $g$, planted in week $i$, and with expected harvest in week $l$; 


\section{CAIXETA-FILHO ET AL.}

Jan de Wit Company

NUMCANT $3_{\text {jvgil }}=$ total flower beds in greenhouse type $P F$, occupied by bulbs from batch $j$, for lily variety $v$, from group $g$, planted in week $i$, and with expected harvest in week $l$;

$E Q L S P_{t j v g i l}=$ total flower beds used in greenhouse type $Q L S P$ in week $t$, occupied by bulbs from batch $j$, for lily variety $v$, from group $g$, planted in week $i$, and with expected harvest in week $l$;

$E Q L S I_{\text {tjogil }}=$ total flower beds used in greenhouse type QLSI in week $t$, occupied by bulbs from batch $j$, for lily variety $v$, from group $g$, planted in week $i$, and with expected harvest in week $l$;

$E P F_{\text {tjogil }}=$ total flower beds used in greenhouse type $P F$ in week $t$, occupied by bulbs from batch $j$, for lily variety $v$, from group $g$, planted in week $i$, and with expected harvest in week $l$.

Mathematical Modeling Structure (mostly defined for combinations of sets related to viable production cycle's durations): Maximize the objective function

$$
R B R U=R E C-C T O T
$$

subject to the following constraints:

Bulb inventory:

$$
\sum_{v} \sum_{g} \sum_{i} \sum_{l} Q T_{j v g i l} \leq B U L B_{j}
$$

Accounting procedures for potted lilies, discounting physical losses and taking into consideration only the lilies with the minimum number of buds:

$$
\begin{aligned}
& Q_{T G R U P O} O_{\text {jvgil }}=\left(Q T_{j v g i l} \times\left(1-P E R D A_{\text {jvgil }}\right)\right) / \\
& D E N S_{j v g i l} \text { for } F V_{\text {jvgil }}=1 \text { and BOTOES } S_{\text {jvgil }} \\
& \geq \text { MINBOTOES }_{\text {jugil }} / \text { DENS }_{\text {jvgil }} \\
& Q_{T G R U P O}{ }_{\text {jvgil }}=0 \text { for } F V_{\text {jvgil }}=1 \text { and } B O T O E S_{\text {jvgil }} \\
& <\text { MINBOTOES }_{\text {jugil }} / \text { DENS } \text { jugil }_{\text {. }}
\end{aligned}
$$

Accounting procedures for cut lilies to discount physical losses and take into consideration only the lilies with the minimum number of buds and minimum number of stems:

$$
\begin{aligned}
& Q_{\text {TGRUPO }} \text { jvgil }=\left(Q T_{\text {jvgil }} \times\left(1-P E R D A_{\text {jvgil }}\right)\right) / \\
& \text { MINHASTE }_{\text {jvgil }} \text { for } F C_{\text {jvgil }}=1 \text { and BOTOES } S_{\text {jvgil }} \\
& \geq \text { MINBOTOES }_{\text {jvgil }} / \text { MINHASTE }_{\text {jvgil }} \\
& Q_{T G R U P O}{ }_{\text {jvgil }}=\left(Q T_{\text {jvgil }} \times\left(1-P E R D A_{\text {jvgil }}\right)\right) / \\
& \text { MINBOTOES } \left._{j v g i l} / \text { BOTOES }_{\text {jvgil }}\right) \text { for } F C_{\text {jvgil }}=1 \\
& \text { and BOTOES } S_{j o g i l}<M_{I N B O T O E S_{j u g i l}} / \text { MINHASTE }_{j o g i l} \text {. }
\end{aligned}
$$

Revenue structure:

$$
R E C=\sum_{j} \sum_{v} \sum_{g} \sum_{i} \sum_{l} P_{R E C O} \text { lvg } \times Q^{2 T G R U P O} O_{j v g i l} .
$$

Cost structure:

$$
\begin{gathered}
\text { CTOT }=C B+C F C+C F V \\
C B=\sum_{j} \sum_{v} \sum_{g} \sum_{i} \sum_{l} C B U L B_{j} \times Q T_{j v g i l}
\end{gathered}
$$

$$
\begin{aligned}
& C F C=\sum_{j} \sum_{v} \sum_{g} \sum_{i} \sum_{l} C C A N T_{j o g i l} \\
& \times N U M C A N T_{\text {jvgil }} \text { for } F C_{\text {jvgil }}=1, \\
& C F V=\sum_{j} \sum_{v} \sum_{g} \sum_{i} \sum_{l} C C A N T_{\text {jvgil }} \\
& \times \text { QTGRUPO }_{\text {jvgil }} \text { for } F V_{\text {jvgil }}=1 .
\end{aligned}
$$

Sale level limits:

$$
\begin{gathered}
\sum_{i} \sum_{j} \text { QTGRUPO }_{j v g i l} \leq V M A X_{\text {lvg }}-C P R E V_{\text {lvg }} \\
\sum_{i} \sum_{j} Q \text { QTGRUPO } O_{j v g i l} \geq V M I N_{l v g}-C P R E V_{\text {lvg. }}
\end{gathered}
$$

Accounting procedures for determining the number of flower beds:

$$
\begin{aligned}
& \operatorname{NUMCANT}_{\text {jugil }}=Q T_{j v g i l} /\left(E S P A C_{j v g i l} \times D E N S_{j v g i l}\right), \\
& E Q L S P_{t j v g i l}= N U M C A N T 1_{j v g i l} \text { for } Q L S P_{j v g i l}=l, \\
& i<l, t \geq i, t \leq l, \\
& E Q L S I_{\text {tjogil }}= N U M C A N T 2_{j v g i l} \text { for } Q L S I_{j v g i l}=l, \\
& i<l, t \geq i, t \leq l, \\
& E P F_{t j v g i l}= N U M C A N T 3_{j v g i l} \text { for } P F_{j v g i l}=l, \\
& i<l, t \geq i, t \leq l,
\end{aligned}
$$

$N U M C A N T_{j v g i l}=N U M C A N T 1_{j v g i l}+N U M C A N T 2_{j v g i l}$

$$
+ \text { NUMCANT3 }_{\text {jvgil }} \text {. }
$$

Avoiding occupations that are not permitted for each type of greenhouse:

$\sum_{j} \sum_{v} \sum_{g} \sum_{i} \sum_{l} E Q L S P_{t j v g i l}=0$ for all $t$ and $Q L S P_{j v g i l} \neq 1$,

$\sum_{j} \sum_{v} \sum_{g} \sum_{i} \sum_{l} E Q L S P_{\text {tjogil }}=0$ for all $t$

$$
\text { and } Q L S P_{\text {jogil }}=1, \quad i<l, t<i \text {, or } t>l \text {, }
$$

$\sum_{j} \sum_{v} \sum_{g} \sum_{i} \sum_{l} E Q L S I_{t j v g i l}=0$ for all $t$ and $Q L S I_{j v g i l} \neq 1$,

$\sum_{j} \sum_{v} \sum_{g} \sum_{i} \sum_{l} E Q L S I_{\text {tjogil }}=0$ for all $t$ and

$$
\operatorname{QLSI}_{\text {jogil }}=1, i<l, \quad t<i \text {, or } t>l,
$$

$\sum_{j} \sum_{v} \sum_{g} \sum_{i} \sum_{l} E P F_{t j v g i l}=0$ for all $t$ and $P F_{j u g i l} \neq 1$,

$\sum_{j} \sum_{v} \sum_{g} \sum_{i} \sum_{l} E P F_{t j v g i l}=0$ for all $t$ and $P F_{\text {jogil }}=1$,

$i<l, \quad t<i$, or $t>l$,

Respecting the weekly availability of flower beds for each type of greenhouse:

$$
\sum_{j} \sum_{v} \sum_{g} \sum_{i} \sum_{l} E Q L S P_{\text {tjogil }} \leq \text { OOEQLSP } P_{t} \text { for all } t
$$




\section{CAIXETA-FILHO ET AL.}

Jan de Wit Company

$\sum_{j} \sum_{v} \sum_{g} \sum_{i} \sum_{l} E Q L S I_{t j p g i l} \leq$ OOEQLSI $I_{t}$ for all $t$

$\sum_{j} \sum_{v} \sum_{g} \sum_{i} \sum_{l} E P F_{t j p g i l} \leq O O E P F_{t}$ for all $t$
Illustrating the Model

Taking the lily variety named Orange Pixie as an example, we present the main types of input data used by the system in Tables 1 to 5 and the main results obtained by the model in Table 6 .

\begin{tabular}{ccc}
$\begin{array}{c}\text { Flower bed } \\
\text { code range }\end{array}$ & $\begin{array}{c}\text { Corresponding } \\
\text { greenhouse }\end{array}$ & $\begin{array}{c}\text { Unavailability } \\
\text { period }\end{array}$ \\
\hline $101-110$ & $P F$ & $01 / 01 / 1999-30 / 06 / 1999$ \\
$201-210$ & $Q L S I$ & - \\
$211-220$ & $Q L S I$ & - \\
$301-310$ & $Q L S P$ & $01 / 05 / 1999-30 / 09 / 1999$
\end{tabular}

Table 1: The company could use the designated flower beds for the lily variety named Orange Pixie.

Bulb size Flower group Planting week Cycle (days) Buds/stem Physical loss (\%) Density $\quad$ Spacing Greenhouse compatibility

\begin{tabular}{|c|c|c|c|c|c|c|c|c|}
\hline 12 & Potted & 45 & 55 & 3 & 3 & 3 bulbs/pot & 1.000 pots/flower bed & QLSP or $P F$ \\
\hline 16 & Cut & 46 & 53 & 5 & 3 & 16 bulbs/box & 160 boxes/flower bed & QLSP, QLSI or PF \\
\hline
\end{tabular}

Table 2: The lily variety named Orange Pixie has these general characteristics.

\begin{tabular}{|c|c|c|c|c|c|}
\hline \multicolumn{2}{|c|}{ Bulb costs } & \multicolumn{4}{|c|}{ Lily production } \\
\hline Size & $\begin{array}{c}\text { Value } \\
(\mathrm{R} \$)\end{array}$ & $\begin{array}{l}\text { Flower } \\
\text { group }\end{array}$ & $\begin{array}{l}\text { Minimum } \\
\text { quantity } \\
\text { of buds }\end{array}$ & $\begin{array}{l}\text { Minimum } \\
\text { quantity } \\
\text { of stems }\end{array}$ & $\begin{array}{l}\text { Cost } \\
\text { (R\$) }\end{array}$ \\
\hline 12 & $0.25 / \mathrm{bulb}$ & Potted & 9 & 3 & $0.55 /$ pot \\
\hline 16 & 0.30/bulb & Cut & 24 & 8 & 280.00/flow \\
\hline
\end{tabular}

Table 3: The lily variety named Orange Pixie has these costs.

\begin{tabular}{|c|c|c|c|c|}
\hline $\begin{array}{l}\text { Lily } \\
\text { group }\end{array}$ & Week & $\begin{array}{l}\text { Minimum } \\
\text { quantity }\end{array}$ & $\begin{array}{l}\text { Maximum } \\
\text { quantity }\end{array}$ & $\begin{array}{l}\text { Expected } \\
\text { price }(\mathrm{R} \$)\end{array}$ \\
\hline Potted & $01 / 2000$ & 2,376 & 4,000 pots & $2.74 /$ pot \\
\hline Cut & $02 / 2000$ & 0 & $\begin{array}{l}1,240 \text { bunches } \\
\text { with } 8 \text { stems }\end{array}$ & $\begin{array}{l}6.00 / \text { bunch } \\
\text { with } 8 \text { stems }\end{array}$ \\
\hline
\end{tabular}

Table 4: In 2000, the lily variety named Orange Pixie had these trade figures.

\begin{tabular}{lccc}
$\begin{array}{l}\text { Bulb } \\
\text { batch code }\end{array}$ & $\begin{array}{c}\text { Bulb } \\
\text { size }\end{array}$ & $\begin{array}{c}\text { Period of time } \\
\text { in which the bulbs } \\
\text { can be planted }\end{array}$ & $\begin{array}{r}\text { Available } \\
\text { quantity }\end{array}$ \\
\hline 98320919 & 12 & 07/01/1999-16/01/2000 & 17,150 \\
98323929 & 16 & $25 / 09 / 1999-01 / 02 / 2000$ & 52,500
\end{tabular}

Table 5: The company maintains these inventory levels for bulbs used in producing the lily variety named Orange Pixie.

\begin{tabular}{lcccccc}
$\begin{array}{l}\text { Bulb } \\
\text { batch code }\end{array}$ & Lily group & $\begin{array}{c}\text { Bulbs to } \\
\text { be planted }\end{array}$ & Planting week & Harvesting week & $\begin{array}{c}\text { Number of } \\
\text { flower beds }\end{array}$ & $\begin{array}{c}\text { Quantity to } \\
\text { be sold }\end{array}$ \\
\hline 98320919 & Potted & 12,371 & $45 / 1999$ & $01 / 2000$ & 4 in a QLSP greenhouse & $\begin{array}{c}\text { Expected } \\
\text { revenue (R\$) }\end{array}$ \\
98323929 & Cut & 10,227 & $46 / 1999$ & $02 / 2000$ & 4 in a QLS/ greenhouse & 1,240 bunches
\end{tabular}

Table 6: The example of the results generated by the optimization model shows the production of the lily variety named Orange Pixie.

INTERFACES

Vol. 32, No. 1, January-February 2002 


\section{CAIXETA-FILHO ET AL.}

\section{References}

Brooke, A., D. Kendrick, A. Meeraus. 1992. GAMS: A User's Guide, Release 2.25. Scientific Press, San Francisco, CA.

Caixeta-Filho, J. V., J. M. van Swaay-Neto, R. L. Lopes. 2000. Linear programming applied to the flower sector: A gladiolus bulb production case study. Internat. Trans. Oper. Res. 7(6) 525-537.

The presentation during the Edelman competition included the following executive endorsements:

Johannes Petrus W. de Wit, general manager and owner of Jan de Wit Company, said, "I receive the finished production plan. It is the soul of my business, the basis for cost and investment budgeting. Based on the quantities to be produced, I can extrapolate the supplies needed. Based on bottlenecks identified by the sensitivity analysis, I can direct investments. The system also forecasts the revenue influx, to which I endeavor to match my payments. The budget became trustworthy. I can now dedicate more of myself to the management of my business."

Marcelo Moraes, production and sales manager of Jan de Wit Company, said, "My team is more motivated because in the beginning of 2000, having exceeded estimated results for 1999, all participated in the profits, receiving individual bonuses equivalent to a month's salary. Based on the system's planning, I now manage my team better, delegate more responsibility and have improved result evaluation. I dedicate less time to check and control and more time to plan and analyze. Last month I was on a holiday, and I had never been on a holiday with such a confidence." 